\title{
Propagation Laws of Blasting Seismic Waves in Weak Rock Mass: A Case Study of Muzhailing Tunnel
}

\author{
Lijun Chen, ${ }^{1}$ Jianxun Chen $\mathbb{D}^{1},{ }^{1}$ Yanbin Luo, ${ }^{1}$ Yalong Guo ${ }^{D},{ }^{2}$ Yongjun Mu, ${ }^{1}$ \\ Daochuan Zhong, ${ }^{1}$ Weiwei Liu, ${ }^{1}$ Tielun Yang, ${ }^{3}$ and Weixiang Chen ${ }^{3}$ \\ ${ }^{1}$ School of Highway, Chang'an University, Xi'an 710064, Shaanxi, China \\ ${ }^{2}$ Liaoning Transportation Planning and Design Institute Co., Ltd., Shenyang 117000, Liaoning, China \\ ${ }^{3}$ Gansu Changda Highway Co., Ltd., Lanzhou 730030, Gansu, China \\ Correspondence should be addressed to Jianxun Chen; chenjx1969@chd.edu.cn
}

Received 10 April 2020; Accepted 4 May 2020; Published 25 May 2020

Academic Editor: Jiang Jin

Copyright $\odot 2020$ Lijun Chen et al. This is an open access article distributed under the Creative Commons Attribution License, which permits unrestricted use, distribution, and reproduction in any medium, provided the original work is properly cited.

In order to study the propagation laws of blasting vibration waves in weak rock tunnels, the longitudinal and circumferential blasting vibration tests in Muzhailing Tunnel were carried out, and the measured data were analyzed and studied using the methods of Sadov's nonlinear regression, Fourier transform, and Hilbert-Huang transform (HHT) to provide a reference for the optimization of blasting design of Muzhailing Tunnel or similar weak rock tunnels. The results showed that the tangential main frequency decreases rapidly and the radial main frequency decreases slowly with the increase of proportionate charge quantity. Under a certain charge quantity, as the distance from the explosion source increases, the spectrum width of the blasting vibration frequency becomes narrower, the overall energy is more concentrated, and the vibration frequency tends to be closer to the low frequency. At a certain distance from the explosive source, the frequency of blasting vibration decreases gradually, and the amplitude of low-frequency region increases with the increase of charge quantity. The vibration velocity on the left side of the tunnel is larger than that on the right side, and the vibration velocity at the vault and the arch foot of lower bench decreases rapidly, while the vibration velocity at the arch feet of upper bench and middle bench decreases slowly. The vibration frequencies of the left arch foot of the middle bench and the right arch foot of the upper bench are higher than those of other positions, while the frequencies of the left arch foot of the upper bench are the lowest. During tunnel blasting, the energy input to the strata media is mainly concentrated in the stage of the blasting of the cut hole. The blasting has more energy input to the left arch foot of the upper bench and the tunnel vault, which is consistent with the conclusion of frequency analysis.

\section{Introduction}

The propagation law of blasting vibration is not only the theoretical basis of tunnel blasting design, but also the premise of effectively controlling blasting vibration hazards $[1,2]$. However, due to the changeable construction conditions and complex geological conditions, the propagation law of blasting vibration has great complexity, randomness, and uncertainty, and it is difficult to analyze the causes of structural damage, which makes it a hot and difficult issue in academic research and tunnel engineering field [3-6].

At present, a lot of research has been done on the propagation law of tunnel blasting vibration. Many researchers [7-13] have also improved the empirical formula of blasting vibration attenuation, which provides a solid theoretical basis for the study of blasting vibration propagation law. On the basis of on-site monitoring, Yang et al. [14], Jiang et al. [15], Jiang et al. [16], Rao [17], and Meng [18] used Sadov's empirical formula to regress the blasting vibration velocity and then studied the vibration velocity attenuation law caused by blasting vibration. Ozer [19] and Nateghi [20] studied the relationship between vibration velocity and vibration frequency by regression analysis and gave the statistical probability of different frequency components. Zhou [21] studied the internal separation distances for underground explosives storage in hard rock, and the 
effect of loading density in a chamber on the required rock separation distance between two adjacent chambers was analyzed based on analytical studies, literature, and largescale tests. In addition, numerical simulation method is widely used to study the stress wave propagation law, foundation vibration characteristics, and structural vibration response of large-scale underground blasting [22-26]. Yang et al. [27] used wave theory and the numerical simulation method to study the characteristics and attenuation law of blasting ground motion under complex site conditions. Peng [28] analyzed the influence of blasting on surrounding rock and initial support structure of highway tunnel by field monitoring and numerical simulation, on the basis of studying the attenuation law of blasting vibration velocity. Deng [29] carried out the numerical modeling on the damage of existing circular tunnel subject to blast-induced shock wave with DEM-based code UDEC. The effects of joint spatial and mechanical properties, initial stress of rock mass, and magnitude of shock wave amplitude on damage of tunnel were evaluated in this study.

The above work studied the propagation law of blasting vibration in tunnels by adopting various research methods, but most of them are carried out in tunnels with good geological conditions. Although the blasting of weak rock tunnels has also been studied, the research results are limited. Deng [30] conducted the UDEC-AUTODYN hybrid modeling of a large-scale underground explosion test, and the results showed that the UDEC-AUTODYN method is appropriate in modeling a large-scale explosive detonation in a closed space and the following wave propagation in jointed rock masses. Xu et al. [31] carried out the vibration monitoring measurement of blasting excavation of deep weak rock tunnel, normalized the vibration data, and obtained the Saeman's empirical formula for deep weak rock tunnel, which provided reference for blasting excavation design optimization. Zhang [32] carried out the numerical simulation of the blasting construction in weak rock tunnel and the design of smooth blasting, which effectively solved the tunnel stability, construction disturbance, and construction period of the weak rock tunnel using the new Austrian method. Shin et al. [33] studied the effects of blasting effects on existing weak rock tunnels and investigated the velocity, displacement, and stress of the particle in the tunnel lining. The above research on the blasting vibration of weak rock tunnels has been carried out from theoretical analysis, field measurement, and numerical simulation, and the research results mainly focus on theoretical formulas, calculation, and optimization of blasting construction parameters. Because the tunnel deformation behavior in weak rock mass is complex, the propagation laws are not well studied. And the changes of the wave velocity and frequency of the blast stress wave are also complicated during the propagation process. In particular, in the Muzhailing Highway Tunnel under construction, the tunnel traverses 12 large fault fracture zones and carbonaceous phyllite strata, and the action of geological structure is strong. It is difficult to predict the variation law of surrounding rock in design and construction using available results. The construction is extremely difficult, and the deformation magnitude is large [34, 35]. The weak rock mass with interbed structure has high requirements for blasting construction, which makes the blast propagation law more complicated. Therefore, studying the blasting vibration propagation law of weak rock tunnel is of great significance for guiding tunnel blasting construction. In this paper, the field blasting measurements in Muzhailing Tunnel were carried out, and the methods of Sadov's nonlinear regression, Fourier transform, and HHT were used to analyze the propagation law of blasting vibration in weak rock mass. This study provides a reference for the optimization of blasting design of similar weak rock mass tunnels in the future.

\section{Tunnel Overview and Blasting Parameters}

\subsection{Tunnel Overview}

2.1.1. Project Overview. Muzhailing Tunnel is a key project of Weiyuan-Wudu section of Lanzhou-Haikou National Expressway (G75) in China. The tunnel is designed with separate two-way four lanes, with a net width of $10.25 \mathrm{~m}$ and a maximum buried depth of $638 \mathrm{~m}$. The elevation of the tunnel site is high, and the elevation ranges from $2416 \mathrm{~m}$ to $3133 \mathrm{~m}$. The atmospheric pressure is low, about $740 \mathrm{kPa}$. The geographical location is shown in Figure 1.

2.1.2. Geological Conditions. The measurement section is located in the right tunnel with the stake numbers from $\mathrm{K} 212+235$ to $\mathrm{K} 212+362$. The stratum lithology is the interbedding of calc-siliceous sandy slate with gray mediumthin layer and black carbonaceous phyllite with mediumthin layers from lower Permian (P1). The strength of sandy slate is high, the uniaxial compressive strength $(R c)$ is greater than $60 \mathrm{MPa}$, the softening coefficient is greater than 0.75 , and the rock is not softened when immersed in water. The strength of carbonaceous phyllite is low, the uniaxial compressive strength $R c$ is $3.6 \mathrm{MPa}$ to $4.6 \mathrm{MPa}$, and it is easy to soften and disintegrate when water is encountered. The disintegration index is $36.8 \%$. It is a low-resistant disintegration rock whose phyllitic foliation is well developed and its surface is smooth. Due to the emergence of interbedded carbonaceous phyllite and sandy slate, the overall strength of surrounding rock is low.

The geological structure is mainly monoclinic structure with high dip. The strata strike is $305^{\circ}$ and dip is about $80^{\circ}$. The slate, phyllite, and structural joints are well developed so that the rock mass is cut into medium-thin layered structure and fragmented structure, which is relatively broken. The integrity of surrounding rock varies greatly from top to bottom of the tunnel face and is asymmetrical. The surrounding rock of the measurement section is relatively dry, and occasionally a small amount of water seepage is found. In general, the strength of surrounding rock is low, and local collapse is easy to occur, resulting in cavity formation.

2.2. Blasting Parameters. The tunnel was constructed by three-bench circular excavation with reserved core soil method, and smooth blasting was used for excavation (Figure 2). 


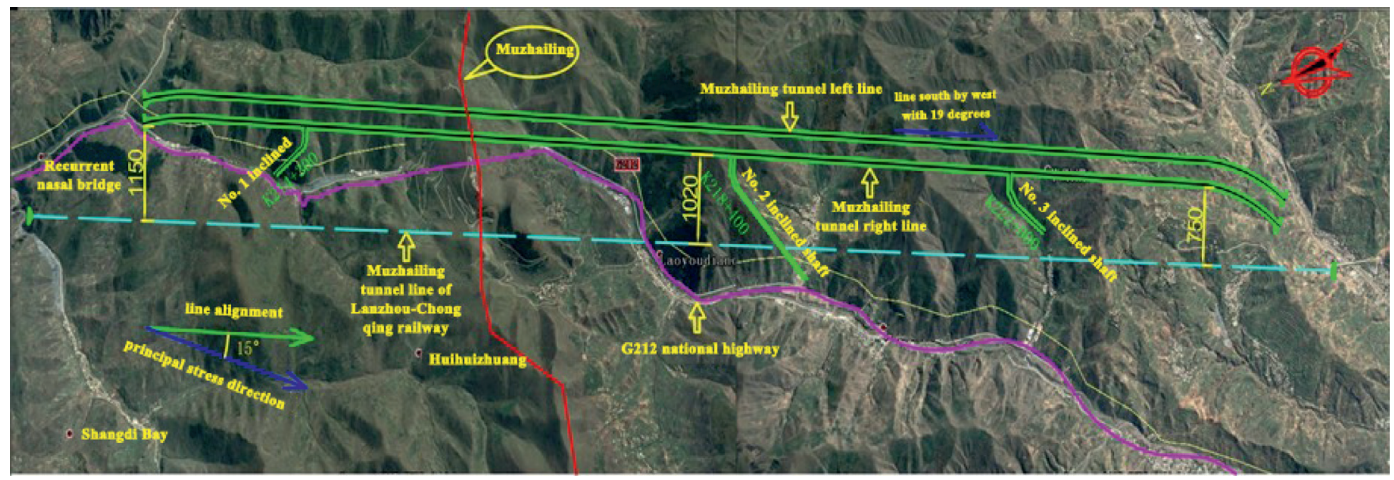

Figure 1: Geographical location of Muzhailing Tunnel.

The blastholes were mainly arranged on both sides of the core soil of the upper bench, on both sides of the middle bench, and on both sides of the lower bench. The blastholes were drilled with a pneumatic leg rock drill (pneumatic drill). The diameter of the borehole was $40 \mathrm{~mm}$, and the depth of the blasthole was between $1.3 \mathrm{~m}$ and $2.5 \mathrm{~m}$, which depend on the lithology, water seepage conditions, and the actual construction footage. After the drilling was completed, the high-pressure wind was used to wash the blastholes, and the rock powder and sand in the blasthole were cleaned to ensure the charge quantity and avoid damage to the nonel. During the blasting operation, all blastholes were uncoupled and continuously charged, and the orifices were not filled. The uncoupling coefficient of the field charge was 1.25. The blasthole arrangement is shown in Figure 3. The figure represents the numbers of the No. 2 rock emulsion explosives, and the number of segments is the detonator segment.

Considering the infiltration of water in the local section of the tunnel, No. 2 rock emulsified explosive with good explosive performance, good safety, strong water resistance, and low environmental pollution is adopted; its specification is $32 \mathrm{~mm} \times 300 \mathrm{~g}$. In order to make full use of blasting energy, reduce charge consumption, improve the blasting performance, and avoid the huge seismic effect caused by detonation together; millisecond delay blasting technology is adopted. Nonelectric millisecond delay detonators are used in all detonators. In order to avoid the overlapping of wave peaks which may occur in different stages of detonation, only odd-numbered detonators in 1-15 are selected.

According to the actual situation of the site, the Muzhailing Tunnel is blasted on the upper bench and the lower bench, or the upper, middle, and lower benches by stages. Excavation blasting uses a parallel network, as shown in Figure 4.

\section{Measurement Schemes and Analysis Method}

\subsection{Measurement Schemes}

3.1.1. Longitudinal Measurement Scheme. In order to measure the vibration velocity at different distances from the explosion source, the sensors (three-vector sensors, which

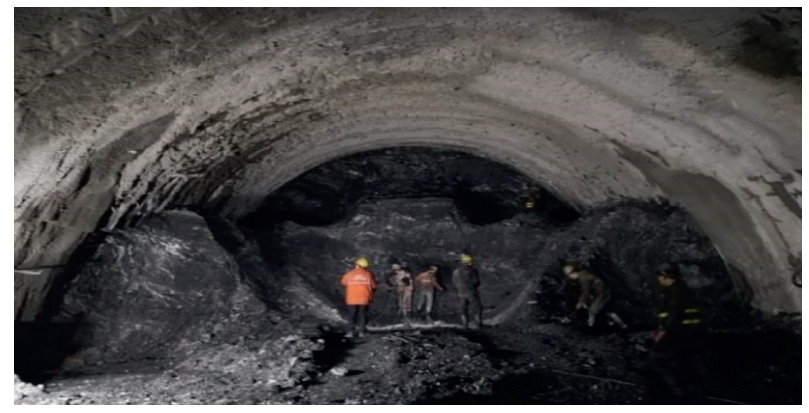

Figure 2: Three-bench circular excavation with reserved core soil method.

can acquire signals of blasting vibration and then transmit them to the TC- 4850 blasting vibrometer) were arranged along the longitudinal direction of the left arch foot of the upper bench in the tunnel, in which there exists largest deformation on the whole section. In order to cover the near and far areas of the explosion source as far as possible and to ensure the safety of the sensors, the first measuring point was located at $\mathrm{K} 212+260$ section, $18.3 \mathrm{~m}$ from the tunnel face and $6.4 \mathrm{~m}$ from the middle bench. After that, a sensor was laid every $3 \mathrm{~m}$, with a total of five measuring points. The nearest sensor number to the tunnel face is 1 , followed by 2 , 3,4 , and 5 . The layout of the measuring points is shown in Figure 5 .

3.1.2. Circumferential Measurement Scheme. When measuring the vibration velocity at different locations in circumferential direction of the tunnel, the measurement section should not be too close to the blast source to ensure the safety of the sensors, and is finally selected at the section of $\mathrm{K} 212+335$ which is $15 \mathrm{~m}$ away from the tunnel face. The sensors are placed in the tunnel vault, the left arch foot of the upper bench, the right arch foot of the upper bench, the left arch foot of the middle bench, the right arch foot of the middle bench, the left arch foot of the lower bench, and the right arch foot of the lower bench. They are numbered as 1 to 7 , respectively. The layout of measuring points is shown in Figure 6 (at this time, the lower bench has not been excavated). 


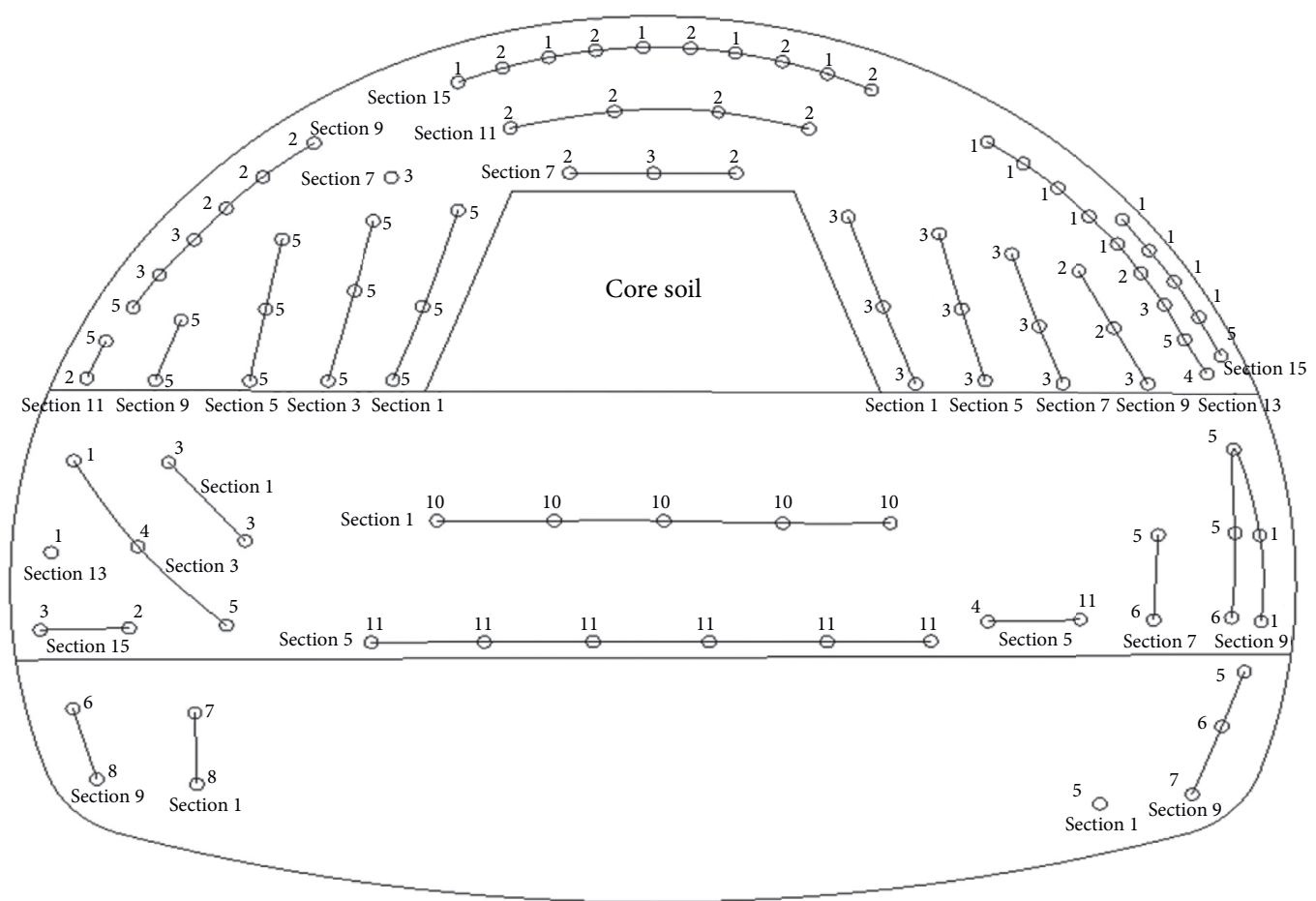

FIGURE 3: Arrangement diagram of blast hole.

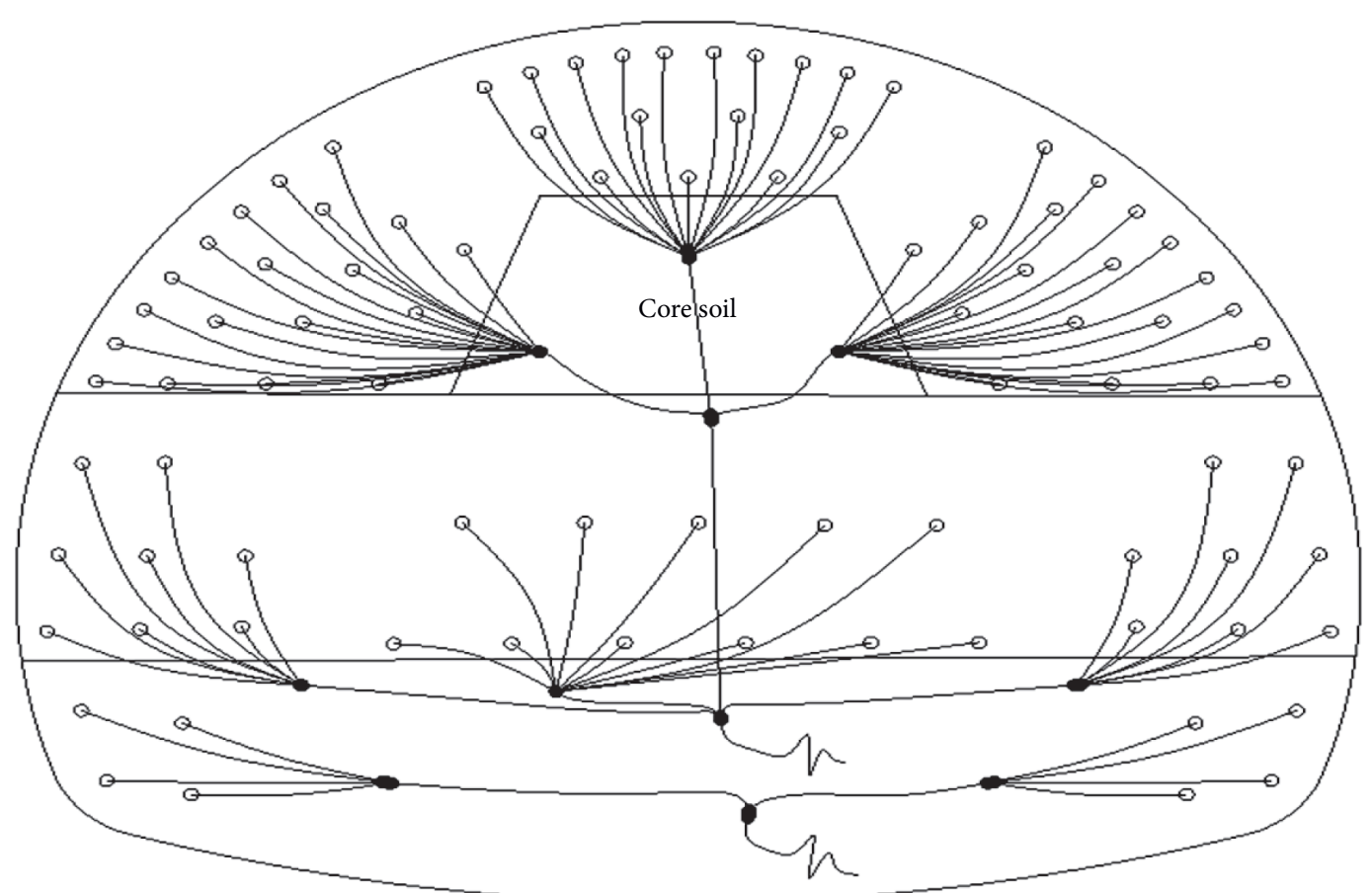

FIgURE 4: Nonelectric detonator initiation network diagram of Muzhailing Tunnel.

3.2. Regression Method. Sadov's formula has a good fitting degree and is often used as a typical peak velocity prediction model [36-38]. Its formula is as follows:

$$
V=K\left(\frac{Q^{m}}{R}\right)^{\alpha}
$$

where $V$ is peak vibration velocity of rock mass. $K, \alpha$ are the attenuation coefficient and the attenuation index, respectively, which are related to the topography and geological conditions. $Q$ is the maximum permissible dose per segment $(\mathrm{kg})$; the maximum charge of a single section is taken in sectional blasting and the total charge is taken in concurrent 


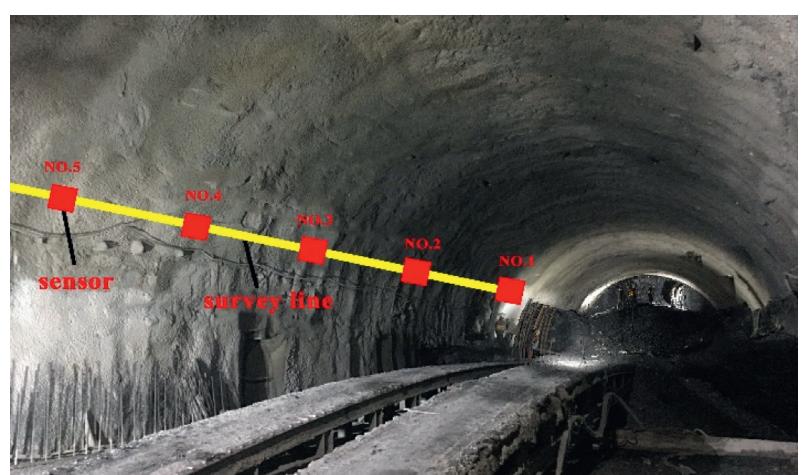

Figure 5: Arrangement diagram of measuring point along longitudinal direction in the tunnel.

blasting. $R$ is distance from explosive source $(\mathrm{m})$, that is, the distance between the explosion source and the measuring point. $m$ is charge index; $1 / 3$ is usually adapted for calculation.

Substituting the peak vibration velocity, the maximum charge, and the distance from explosive source in a single section into (1), the coefficient attenuation coefficient $K$ and attenuation index $\alpha$ can be obtained by regression calculation. The previous results show that different regression methods also affect the accuracy of regression, and the accuracy of nonlinear regression is higher than that of linear regression [1]. Therefore, the following calculations are carried out by means of nonlinear regression. The principles are as follows.

The ratio of the cube root of single period charge to the distance from explosive source is defined as the proportional charge; i.e.,

$$
\rho=\frac{Q^{1 / 3}}{R} .
$$

Then, the fitting degree of Sadov's formula can be expressed by the sum of squares of residual errors between the fitting values and the measured values:

$$
M^{2}=\sum_{i=1}^{n}\left(V_{i}-K \rho_{i}^{\alpha}\right)^{2} .
$$

According to the extreme value theorem of binary function, the condition of minimum is

$$
\begin{aligned}
& \left\{\begin{array}{l}
\frac{\partial M^{2}}{\partial K}=0, \\
\frac{\partial M^{2}}{\partial \alpha}=0,
\end{array}\right. \\
& \left\{\begin{array}{l}
\sum_{i=1}^{n}\left(V_{i}-K \rho_{i}^{\alpha}\right) \rho_{i}^{\alpha}=0, \\
\sum_{i=1}^{n}\left(V_{i}-K \rho_{i}^{\alpha}\right) \rho_{i}^{\alpha} \ln \rho_{i}=0 .
\end{array}\right.
\end{aligned}
$$

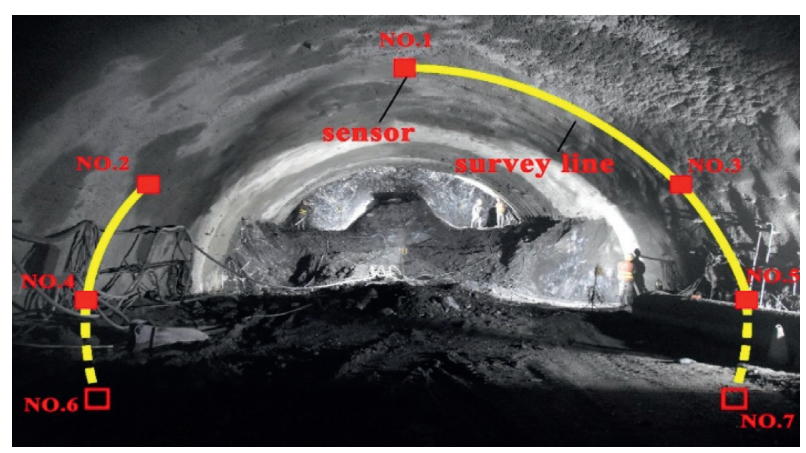

FIGURE 6: Measuring point arrangement diagram along circumferential direction in the tunnel.

One can get

$$
\left\{\begin{array}{l}
\sum_{i=1}^{n} V_{i} \rho_{i}^{\alpha}=K \sum_{i=1}^{n} \rho_{i}^{2 \alpha} \\
\sum_{i=1}^{n} V_{i} \rho_{i}^{\alpha} \ln \rho_{i}=K \sum_{i=1}^{n} \rho_{i}^{2 \alpha} \ln \rho_{i} .
\end{array}\right.
$$

Obviously, the above formula is a nonlinear equation group. It is difficult to solve the problem directly. For the convenience of calculation, iterative calculation is performed using the Levenberg-Marquardt algorithm in Origin software.

\section{Measurement Results and Analysis}

\subsection{Longitudinal Propagation Laws of Blasting Vibration}

4.1.1. Attenuation Laws of Maximum Vibration Velocity. By the BVAnalysis analysis software (the TC-4850 blasting vibrometer matching software produced by Sichuan Zhongke Measurement \& Control Co., Ltd., in August 2017; the data can be previewed and analyzed simply and intuitively) and the on-site blasthole layout, the field data are analyzed and calculated to obtain the maximum vibration velocity and its corresponding segment, charge quantity, and distance from explosive source. Then, using Sadov's formula, the radial, tangential, and vertical maximum vibration velocities of the left arch foot of the tunnel are nonlinearly fitted to obtain the regression equation curve and parameters (Figure 7).

The peak velocities and regression curves of horizontal tangential, horizontal radial, and vertical directions are plotted in Figure 8 for comparison.

(1) From Figure 7, we can see that the fitting degrees of peak velocity are 0.872 in radial direction, 0.711 in vertical direction, and 0.705 in tangential direction, respectively. The main reason is that the conditions of each blasting cannot be completely consistent, and there are many factors affecting the values of coefficients $\mathrm{K}$ and $\alpha$, such as the rock hardness, the rock integrity, the strike direction of the stratum, and the on-site terrain conditions, which results in large dispersion of some points. 


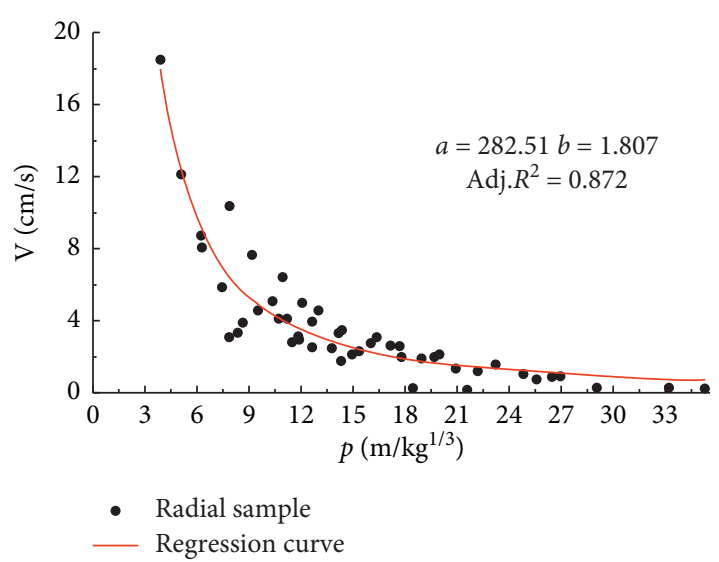

(a)

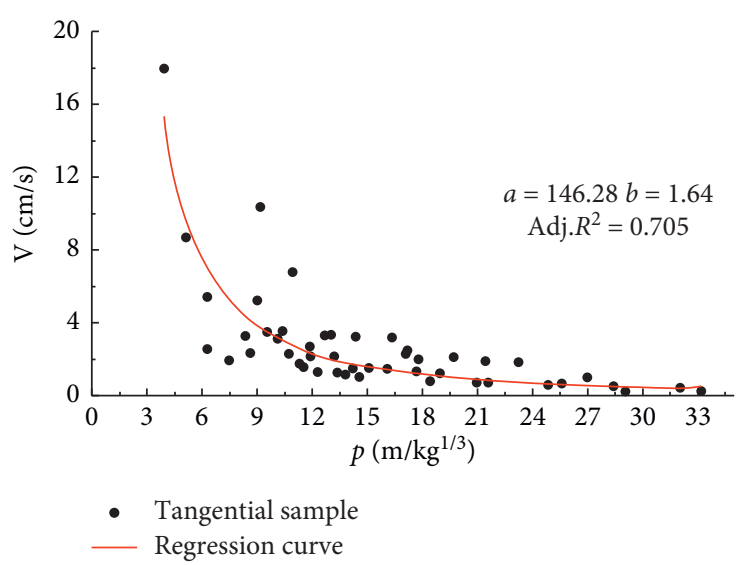

(b)

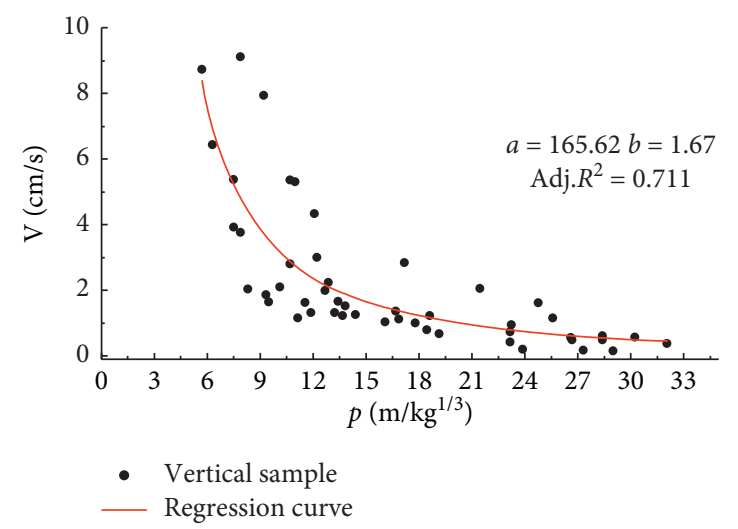

(c)

FIGURE 7: The regression curve of (a) radial velocity, (b) tangential velocity, and (c) vertical velocity.

(2) From Figure 8, it can be seen that the radial velocity is slightly larger than the tangential and vertical velocities. Under the same proportion of charge, the radial velocity is the largest, while the tangential and vertical velocities are relatively small, and the tangential and vertical velocities are basically the same.

(3) Comparing the regression curves and regression parameters of the three directions, the radial regression curve is the steepest, which means that although the corresponding radial velocity is the largest under the same proportion of the charge, the attenuation of radial vibration velocity is also the fastest with the increase of the proportion charge. Figure 8 indicates that the radial regression curve is higher than the vertical and tangential curves at the beginning, and then the three curves coincide basically. It can be predicted that the radial vibration velocity will be lower than that in tangential and vertical directions with the increase of the proportionate charge.

\subsubsection{Blasting Vibration Frequency}

(1) Attenuation Laws of the Main Frequency. In the existing research results [39-44], the attenuation law of the main frequency is different, the fitting effect is not ideal, and there is no unified result. Therefore, a further study needs to be conducted. The mathematical expression between the main frequency and the distance from explosive source, the charge, the geological conditions of the explosion area, and the coefficient of the medium property can be obtained through the dimensional analysis method [45]:

$$
f R=K\left(\frac{\sqrt[3]{Q}}{R}\right)^{\alpha}
$$

where $f$ is the vibration frequency and the other symbols are the same as before.

Equation (7) is used to analyze the attenuation law of the main frequency in the case of weak rock mass. When the upper and middle benches are blasted together, 49 groups of effective data of No. 1 5 sensors are collected, and the data are substituted into (7). Through nonlinear fitting, the correlation coefficient can be obtained, as shown in Figure 9.

From Figure 9, it can be concluded that the fitness $R^{2}$ of regression curves ranges from 0.6 to 0.75 , which indicates that the data has a large dispersion, and the relationship between main frequency and proportionate charge is not very close, but the overall trend is obvious; i.e., $f R$ is positively correlated with proportionate charge.

The magnitude of exponential power directly affects the trend of regression curve. From the fitting attenuation 


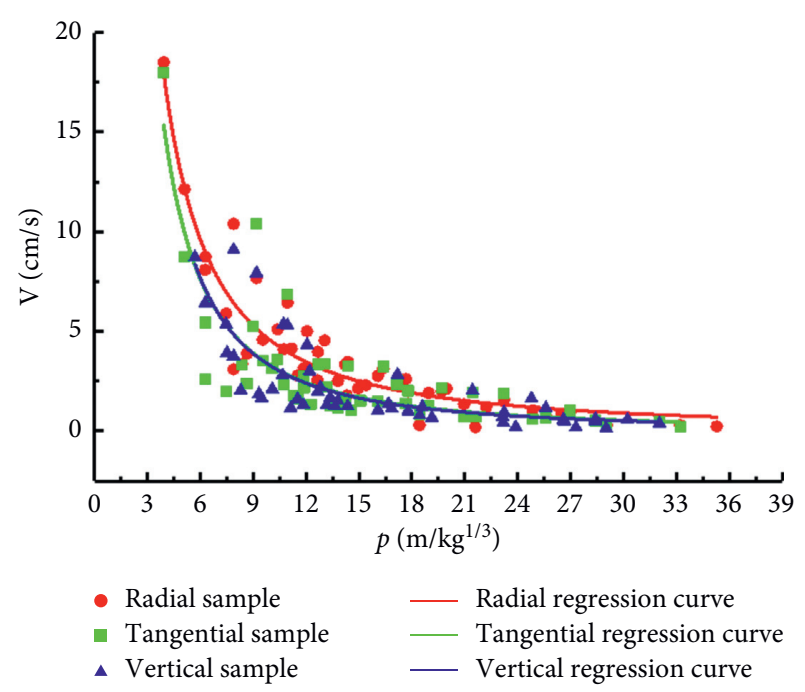

FIgURE 8: The velocity sample and regression curve of three-directional vibration.

exponential value $\alpha$, it can be seen that the $\alpha$ in tangential direction $>\alpha$ in vertical direction $>\alpha$ in radial direction. Therefore, the tangential main frequency decreases more rapidly, and the radial main frequency decreases relatively slowly with the increase of the proportionate charge.

(2) The Influence of Distance from Explosive Source on Vibration Frequency. In order to study the influence of distance from explosive source on the vibration frequency of tunnel, the frequencies of different sensors in the same blasting (i.e., the same charge) were selected for comparative analysis. The distances of sensors No. 1 to 5 from explosive source are $19 \mathrm{~m}, 22 \mathrm{~m}, 25 \mathrm{~m}, 28 \mathrm{~m}$, and $31 \mathrm{~m}$, respectively. The frequency spectrums of the radial component of the vibration wave are shown in Figure 10.

As can be seen from Figure 10, with the increase of distance from explosive source, the spectrum width becomes narrower and the total energy is more concentrated. With the increase of the distance from explosive source, the frequency approaches the low frequency, and the high-frequency energy is dissipated rapidly in the medium. As the distance from the detonation source increases, the less high-frequency energy remains. At this time, the low-frequency energy becomes more prominent. Therefore, it is not true that the greater the distance from the detonation source is, the safer the structure will be. If the residual low frequency is close to the natural frequency of the structure, it is easy to form resonance; even if the amplitude is small, it also has a strong destructive effect. With the increase of distance from the explosion source, the amplitude of the frequency spectrum decreases gradually, showing the remaining low-frequency energy.

(3) Effect of Charge Quantity on Vibration Frequency. In order to further discuss the influence of charge quantity on blasting vibration frequency, samples with the same distance from the blasting center and different charge quantity were selected for comparative analysis. Five groups of samples were selected with the same distance of $40 \mathrm{~m}$ from the tunnel face, but the charge quantities were $Q_{1}=25 \mathrm{~kg}, Q_{2}=67 \mathrm{~kg}$, $Q_{3}=78 \mathrm{~kg}, Q_{4}=90 \mathrm{~kg}$, and $Q_{5}=140 \mathrm{~kg}$, respectively. The frequency spectrums are drawn in turn (Figure 11).

As can be seen from Figure 11, when the charge quantity is small, the frequency of blasting vibration is mainly distributed in the high-frequency band. Correspondingly, the amplitude of blasting vibration is also small. When the charge quantity is large, the main frequency distribution area of blasting vibration is close to the low-frequency area and the amplitude of blasting vibration is larger.

With the increase of charge quantity, the energy of blasting vibration transfers to low frequency, and the energy proportion of high frequency decreases. The increased low frequency caused by the increase of charge is gradually approaching the natural frequency of the structure, which may cause greater damage to the structure.

\subsection{Propagation Laws of Blasting Vibration in Circular Direction}

\subsubsection{Vibration Velocity Laws at Different Locations}

(1) Comparative Analysis of Blasting Attenuation Parameters at Different Locations. The maximum vibration velocity can be obtained by calculating and analyzing the field data through BVAnalysis software and on-site blasthole layout. Then, nonlinear fitting of maximum radial, tangential, and vertical vibration velocities of tunnel vault; left arch foot of upper, middle, and lower benches; and right arch foot is carried out using Sadov's formula. Through analysis, it can be found that the vibration velocity attenuation laws of different positions of tunnel are different, and the parameters of the regression equation are listed in Table 1.

As can be seen from Table 1, the vibration velocity of different positions of the tunnel varies in radial, tangential, and vertical directions. Even if the layout of the blasthole is symmetric about the axis of the tunnel, the vibration attenuation laws on both sides are quite different. On the one hand, this asymmetry situation is caused by the fact that in order to avoid the feet of steel frames suspending in midair at the same time, the middle bench is excavated with left and right dislocation, resulting in site differences; on the other hand, the stratum inclination affects the propagation of the stress wave, which has a great influence on the vibration velocity.

From the vault to the arch foot of the lower bench, the $K$ value of the regression equation for radial, tangential, and vertical vibration velocities tends to decrease; in particular, in the radial direction, $K$ value decreases more obviously. The magnitude of the $\alpha$ value represents the speed of vibration attenuation. The $\alpha$ values of the vault and the arch foot on the lower bench are generally larger, the vibration speed is attenuated rapidly, the $\alpha$ values of the upper and middle bench arch foot are relatively small, and the attenuation of vibration speed is relatively slow.

(2) Peak Vibration Velocity at Different Locations. The blasting vibration in circular direction of the tunnel was monitored 18 times in total. The first 12 times of monitoring 


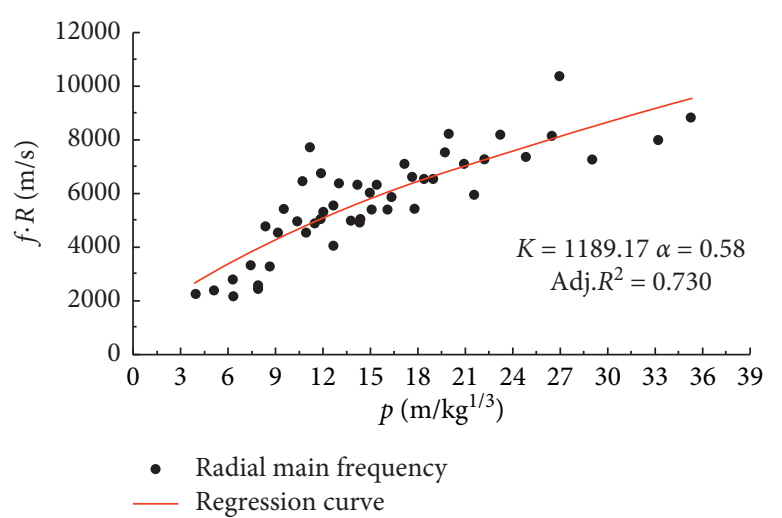

(a)

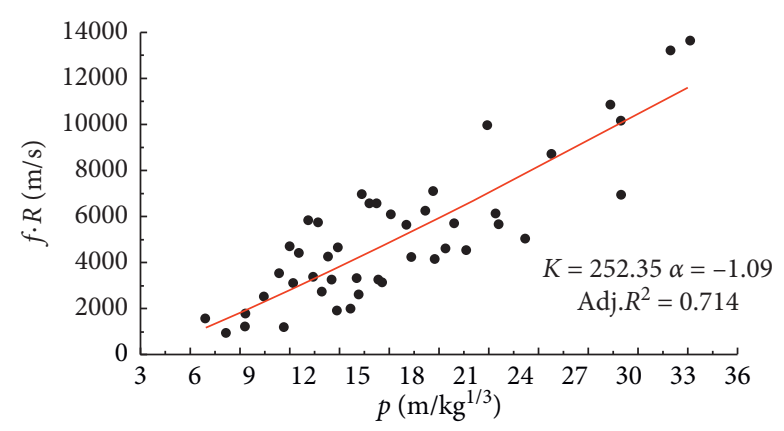

- Tangential main frequency

- Regression curve

(b)

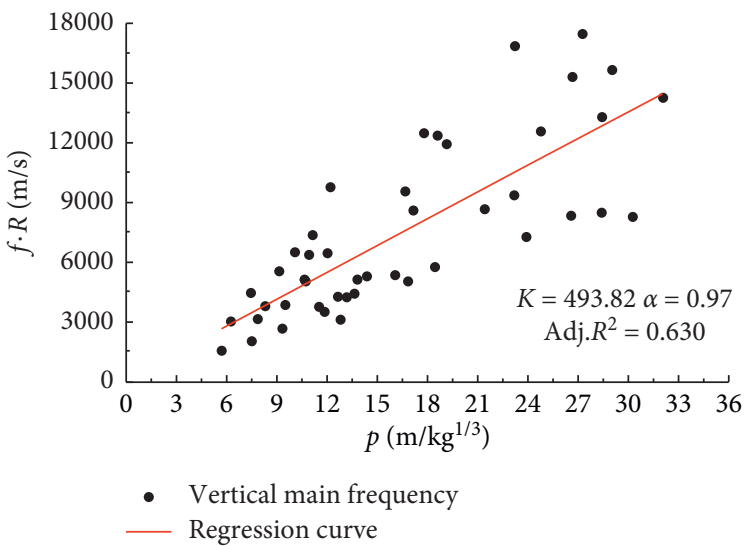

(c)

Figure 9: The regression curve of (a) radial main frequency, (b) tangential main frequency, and (c) vertical main frequency.

only obtained the vibration velocity of the tunnel vault, the left and right arch feet of the upper bench, and the left and right arch feet of the middle bench. After the excavation of the lower bench, the vibration velocities of the left and right arch feet of the lower bench were also monitored for a total of 6 times. The radial, tangential, and vertical peak vibration velocity at different positions in each blasting are shown in Figures $12-14$, respectively.

As shown in Figures 12-14, in general, for the radial vibration velocity, the vibration velocity at the left arch foot and the vault is larger than that at other positions, and the vibration velocity of the right arch foot is relatively small. For the tangential vibration velocity, the vibration velocity of the left arch foot of the middle bench is basically the maximum, and the vibration velocity at the left arch foot of the upper bench is the second. For the vertical vibration velocity, the left arch foot of the upper bench and the left arch foot of the middle bench have a higher vibration velocity, and the vibration velocity at vault is lower.

During tunnel excavation, the radial, tangential, or vertical velocity is significantly greater on the left than those on the right. In general, the vault, the left arch foot of the upper bench, and the left arch foot of the middle bench have a large vibration velocity in the tunnel circumferential direction. The reason is the same as the reason for the difference in the vibration velocity attenuation law. On the one hand, the left and right dislocation excavations of the middle bench result in site differences. On the other hand, the stratum inclination affects the propagation of the stress wave, which has a great influence on the vibration velocity.

4.2.2. Vibration Frequencies at Different Locations. A group of vibration waves caused by the upper bench blasting in the right tunnel are selected and analyzed based on the monitored vertical vibration velocity. The frequency distribution of each part of the tunnel can be obtained by discrete Fourier transform of the time-history curve of each part, as shown in Figure 15.

As can be seen from Figure 15, the left arch foot of the middle bench, vault, and right arch foot of the upper bench have a wide frequency band. The frequencies of the left arch foot of the middle bench are distributed at $50-250 \mathrm{~Hz}$, the frequencies of the right arch foot of the upper bench are distributed at $50-200 \mathrm{~Hz}$, and the frequencies at the vault are obviously low, mainly distributed at $20-150 \mathrm{~Hz}$. The frequency bands of the left and right arch feet on the lower bench and right arch feet on the middle bench are relatively narrow, mainly $60-150 \mathrm{~Hz}$. The frequencies of the left arch foot of the upper bench are relatively low, mainly ranging from 30 to $70 \mathrm{~Hz}$, which is prone to result in resonance and will have an adverse effect on the 

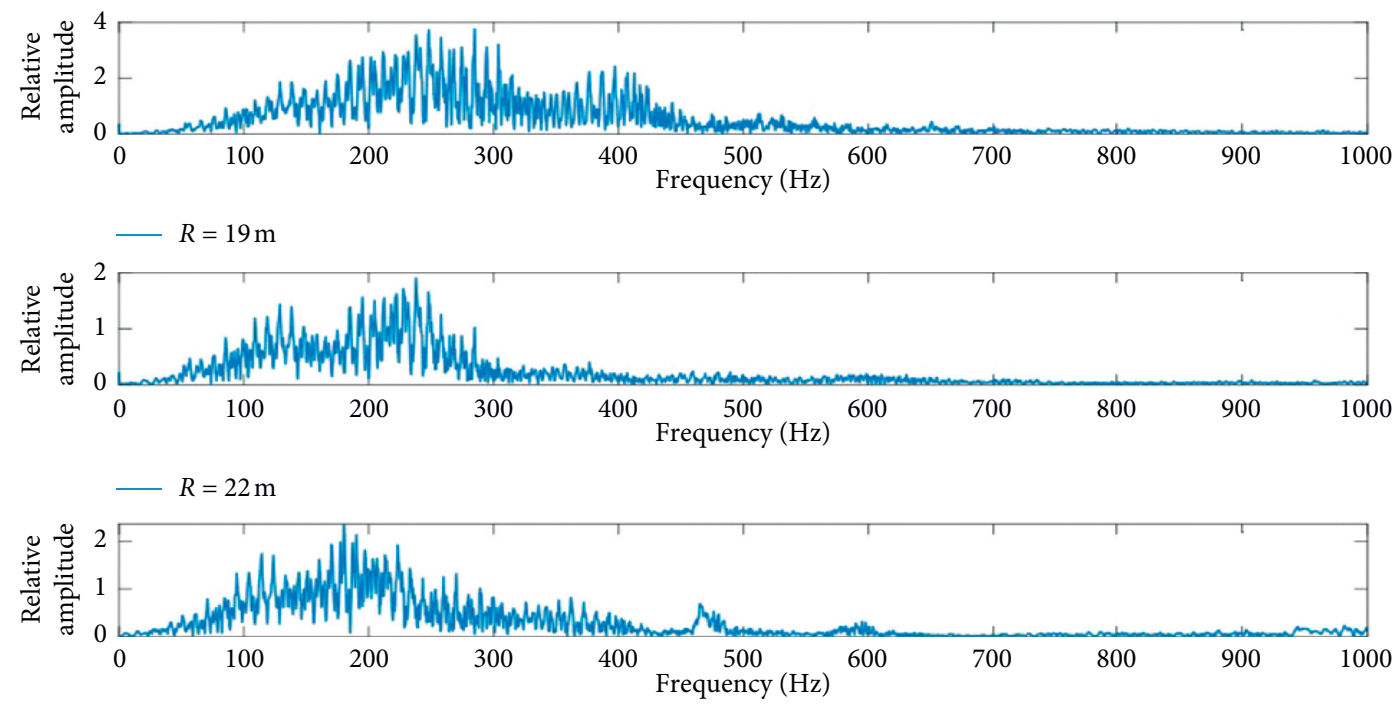

- $R=25 \mathrm{~m}$
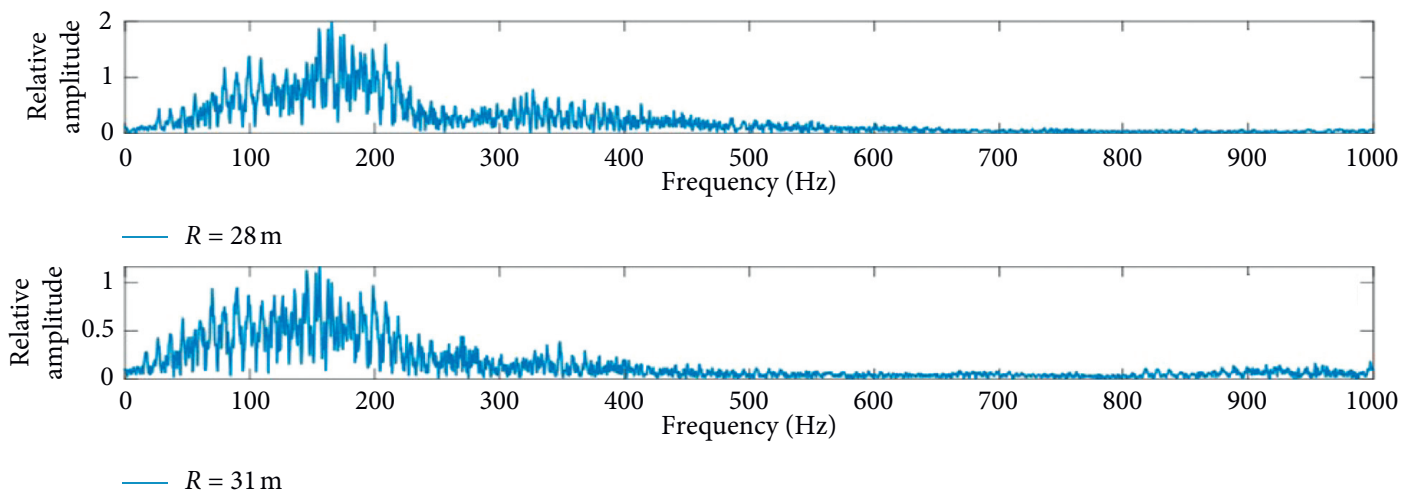

FIgURE 10: Vibration frequency distribution map at different blasting center distances.

TABLE 1: Parameter value of vibration velocity regression equation at different positions of the tunnel.

\begin{tabular}{|c|c|c|c|c|c|c|}
\hline \multirow{2}{*}{ Regression parameter } & \multicolumn{2}{|c|}{ Radial } & \multicolumn{2}{|c|}{ Tangential } & \multicolumn{2}{|c|}{ Vertical } \\
\hline & $K$ & $A$ & $K$ & $\alpha$ & $K$ & $\alpha$ \\
\hline Dome & 258.04 & 2.01 & 210.09 & 1.93 & 175.20 & 1.81 \\
\hline Left arch foot on the upper bench & 269.79 & 1.86 & 139.44 & 1.68 & 150.63 & 1.76 \\
\hline Right arch foot on the upper bench & 210.01 & 1.79 & 175.46 & 1.70 & 146.34 & 1.57 \\
\hline Left arch foot on the middle bench & 174.38 & 1.80 & 274.64 & 1.68 & 237.11 & 1.53 \\
\hline Right arch foot on the middle bench & 173.07 & 1.81 & 103.63 & 1.62 & 91.39 & 1.33 \\
\hline Left arch foot on the lower bench & 132.27 & 1.76 & 188.39 & 2.02 & 105.81 & 1.79 \\
\hline Right arch foot on the lower bench & 130.76 & 2.06 & 90.52 & 1.84 & 123.54 & 2.03 \\
\hline
\end{tabular}

structure. However, the reasons for this situation are the complicated situation of the site and the uneven cracking of the surrounding rock joints. On the other hand, it is closely related to the large charge near the left arch foot of the upper bench. In addition, according to the observation of tunnel settlement and convergence on the site, the settlement and convergence at left arch foot of the upper bench were relatively large (Figure 16), which is undoubtedly related to the adverse impact of the blasting vibration.
4.2.3. Instantaneous Energy at Different Locations. Since the spectrum obtained by the Fourier transform is the integral over the entire time period and contains no time information, we cannot know the specific time corresponding to a certain frequency. In view of this limitation, this section uses the method of HHT (Hilbert-Huang transform) to analyze the change of instantaneous energy at different locations of the tunnel with time. First, empirical mode decomposition is performed on the time-history signals of vibration velocity at different positions of the tunnel to obtain 9 IMF components 

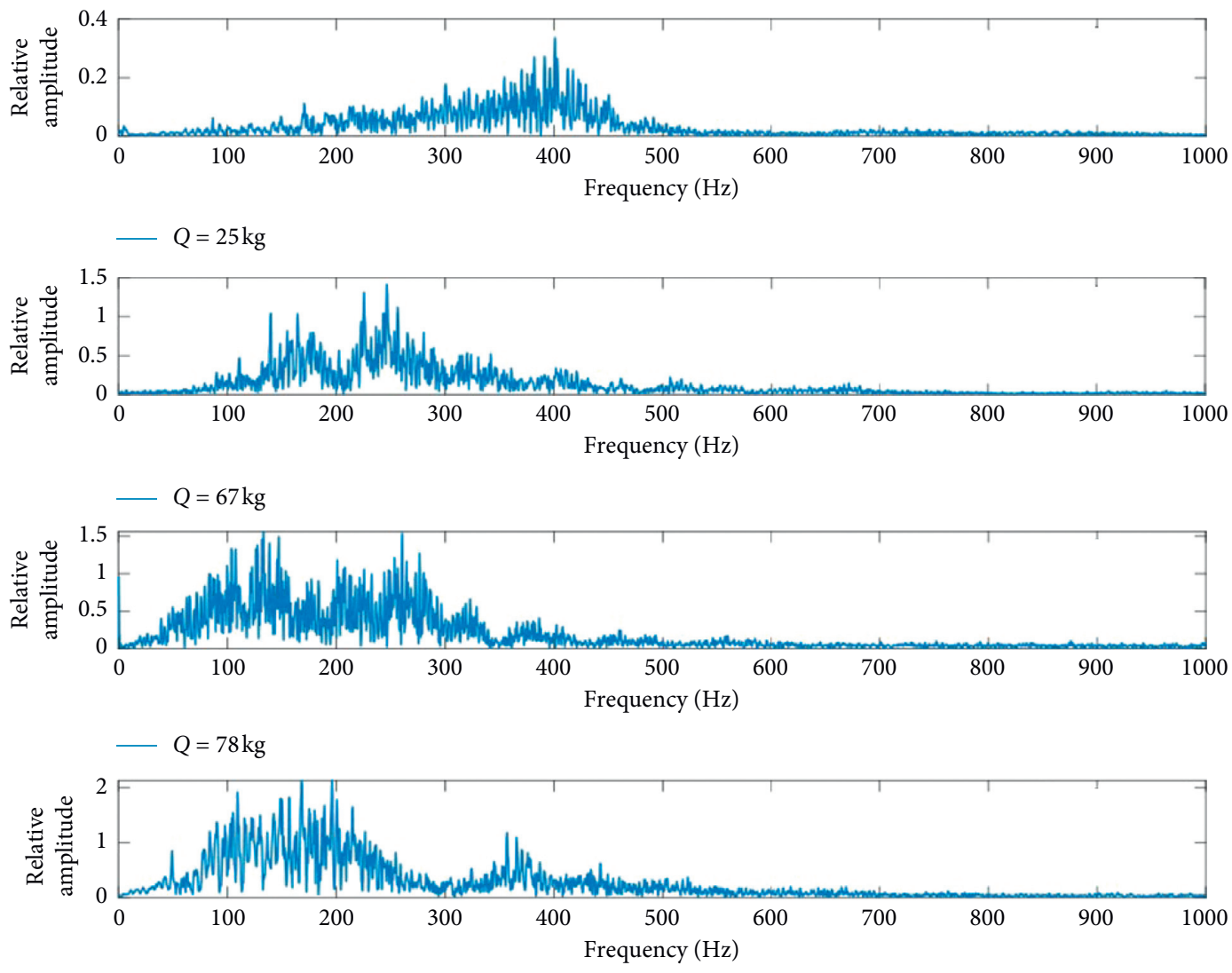

$Q=90 \mathrm{~kg}$

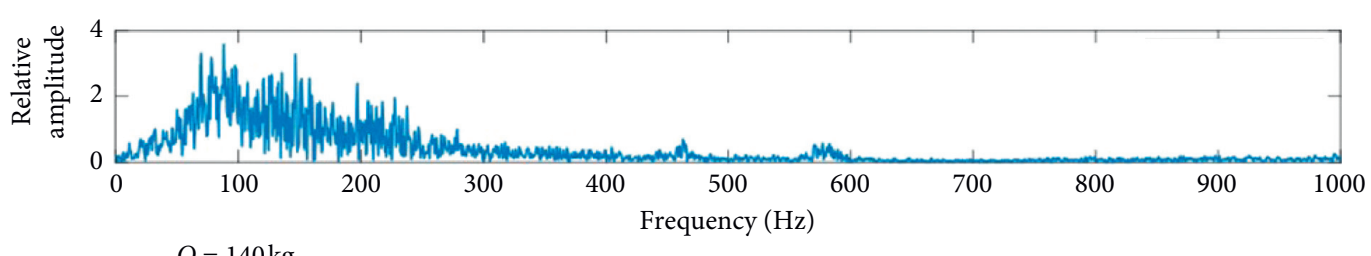

FIgURE 11: Vibration frequency distribution map in different charge quantities.

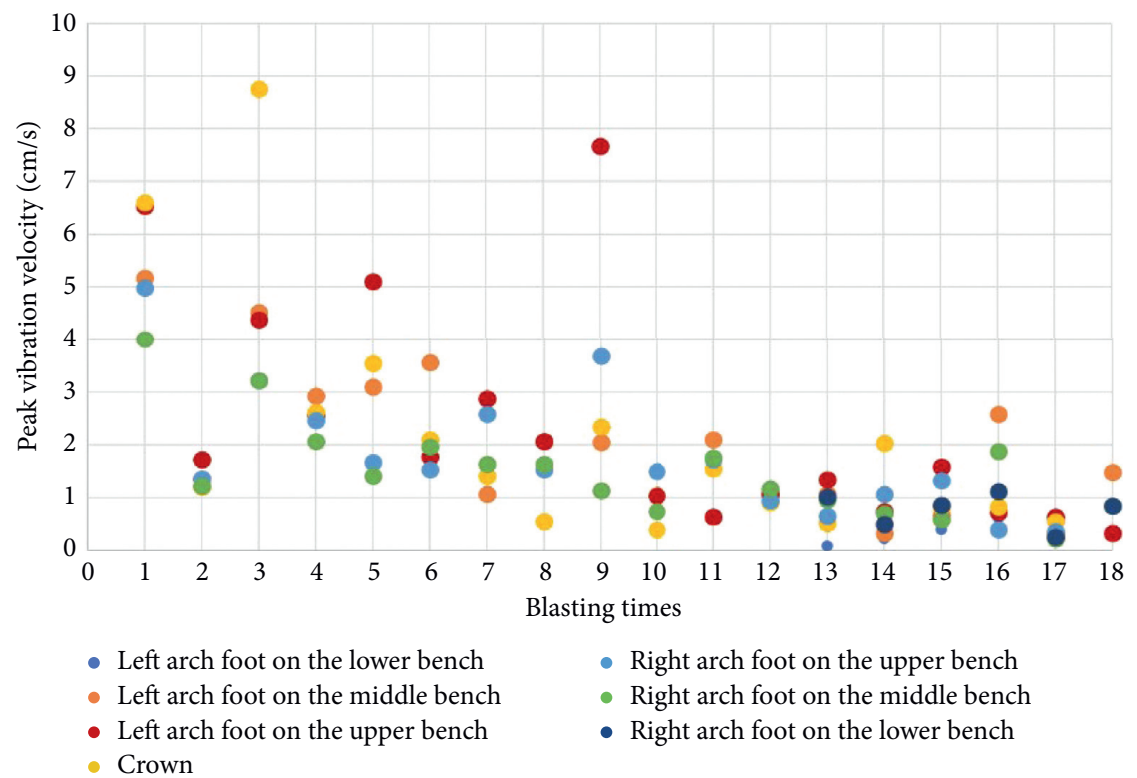

FIGURE 12: Contrast diagram of radial vibration velocity at different positions of the tunnel. 


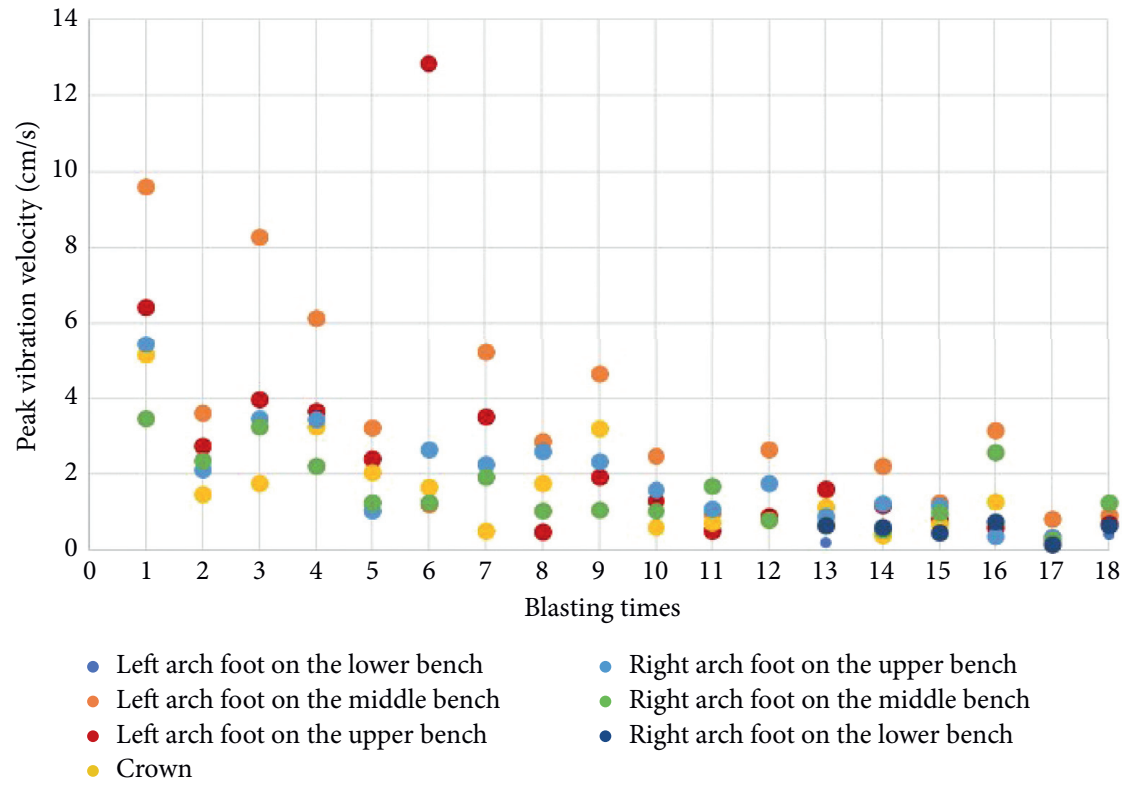

FIGURE 13: Contrast diagram of tangential vibration velocity at different positions of the tunnel.

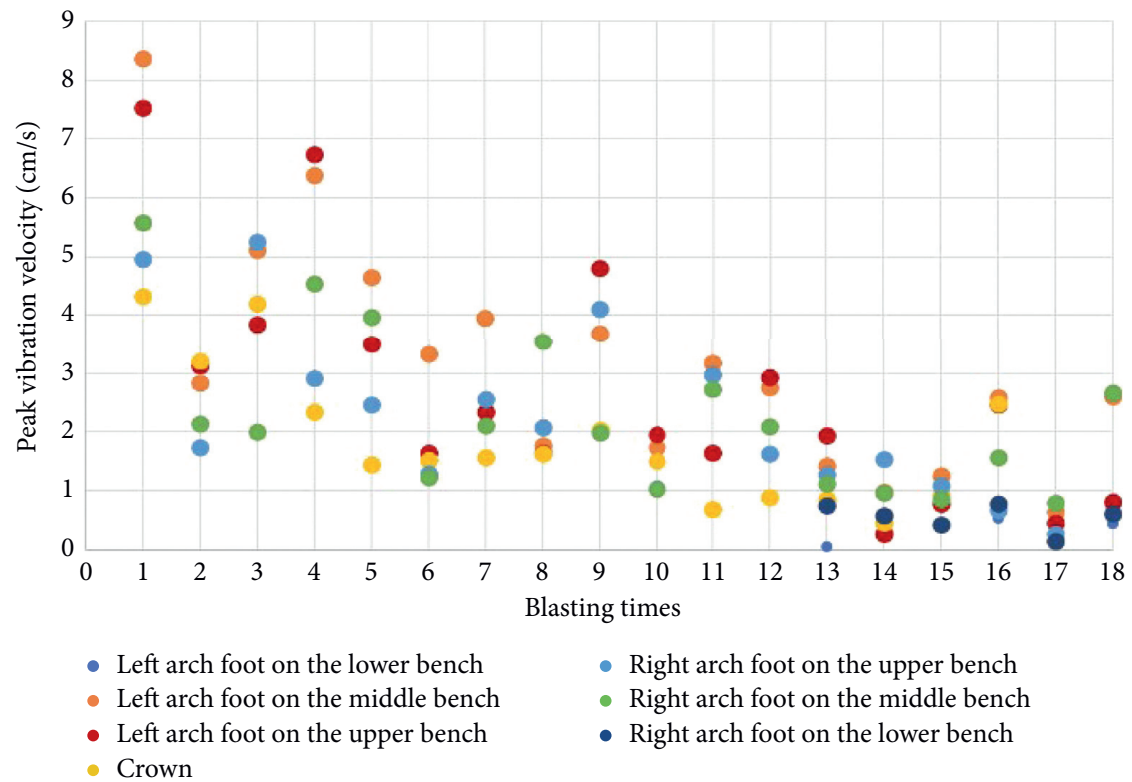

FIGURE 14: Contrast diagram of vertical vibration velocity at different positions of the tunnel.

and 1 residual margin. Then, the residual is discarded, and the Hilbert transform is carried out for each IMF component to obtain the instantaneous energy. Finally, the instantaneous energy of different positions of the tunnel can be obtained by superimposing the instantaneous energy of the IMF components of each order.

The same group of vibration waves as in Section 4.2.2 are selected for analysis, and the instantaneous energy at different positions of the tunnel section was obtained as shown in Figure 17. The following conclusions can be drawn:

(1) The energy of tunnel blasting input to the strata media is mainly concentrated in the first peak of vibration velocity, i.e., the energy generated by the blasting of the cut hole, while the input energy of other blastholes is relatively less.

(2) The blasting has more energy input to the left arch foot of the upper bench and the tunnel vault. In other words, the blasting vibration has a greater influence on the two locations. It also verifies the conclusion of Section 4.2.2 from another aspect; i.e., the frequency of the left arch foot of the upper bench is lower and the damage to the structure is greater.

(3) The instantaneous energy of the left and right arch feet of the lower bench differs by nearly an order of 

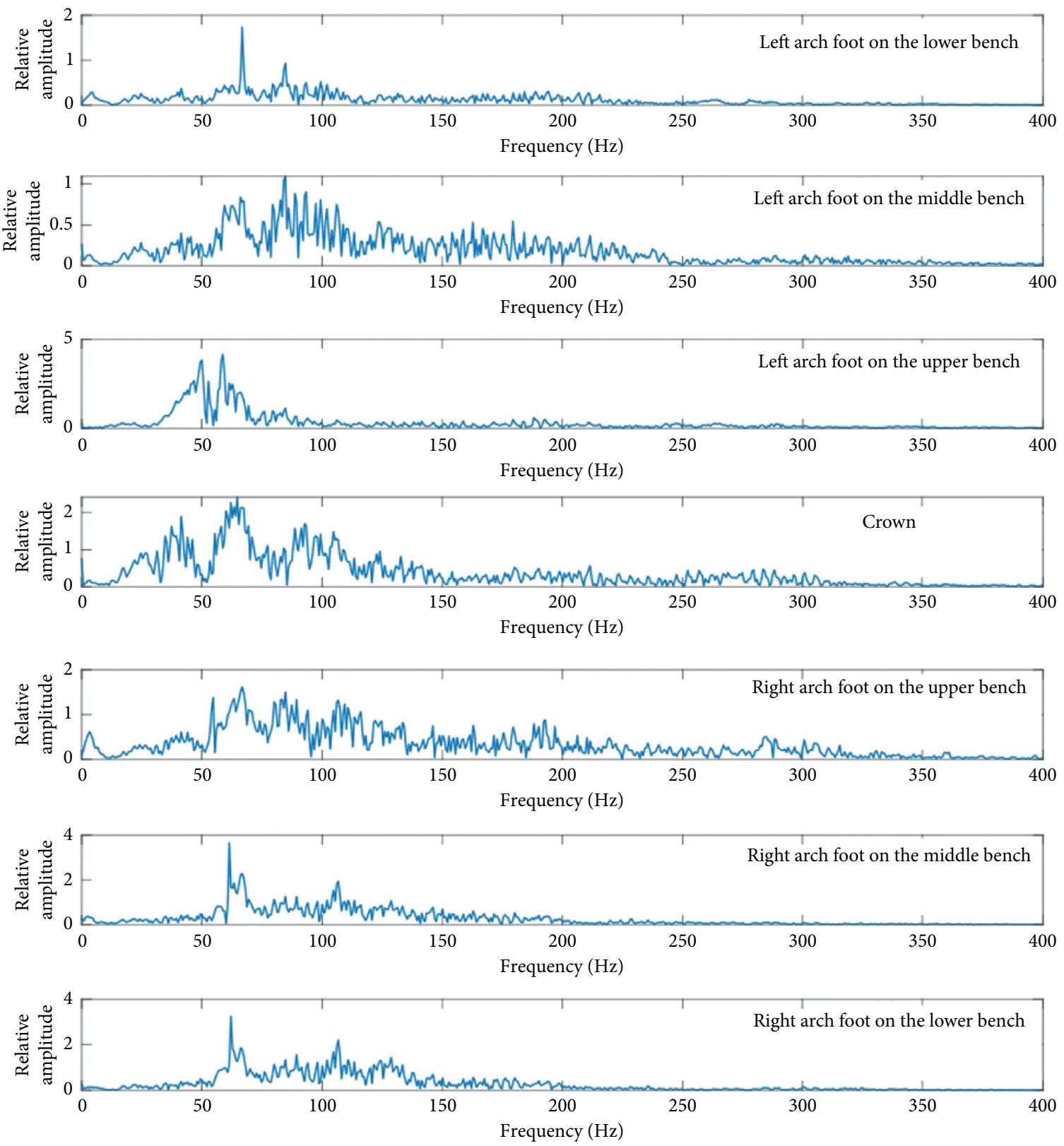

FIGURE 15: Frequency spectrum of vertical vibration at different positions of tunnel.

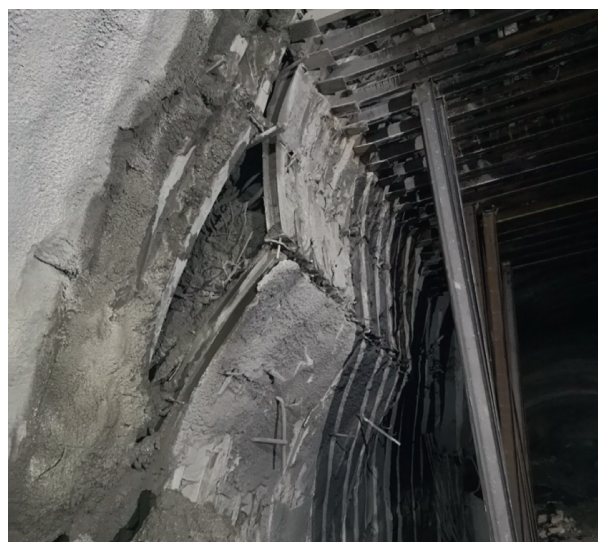

FIGURE 16: Large settlement and convergence at left arch foot of the upper bench. 

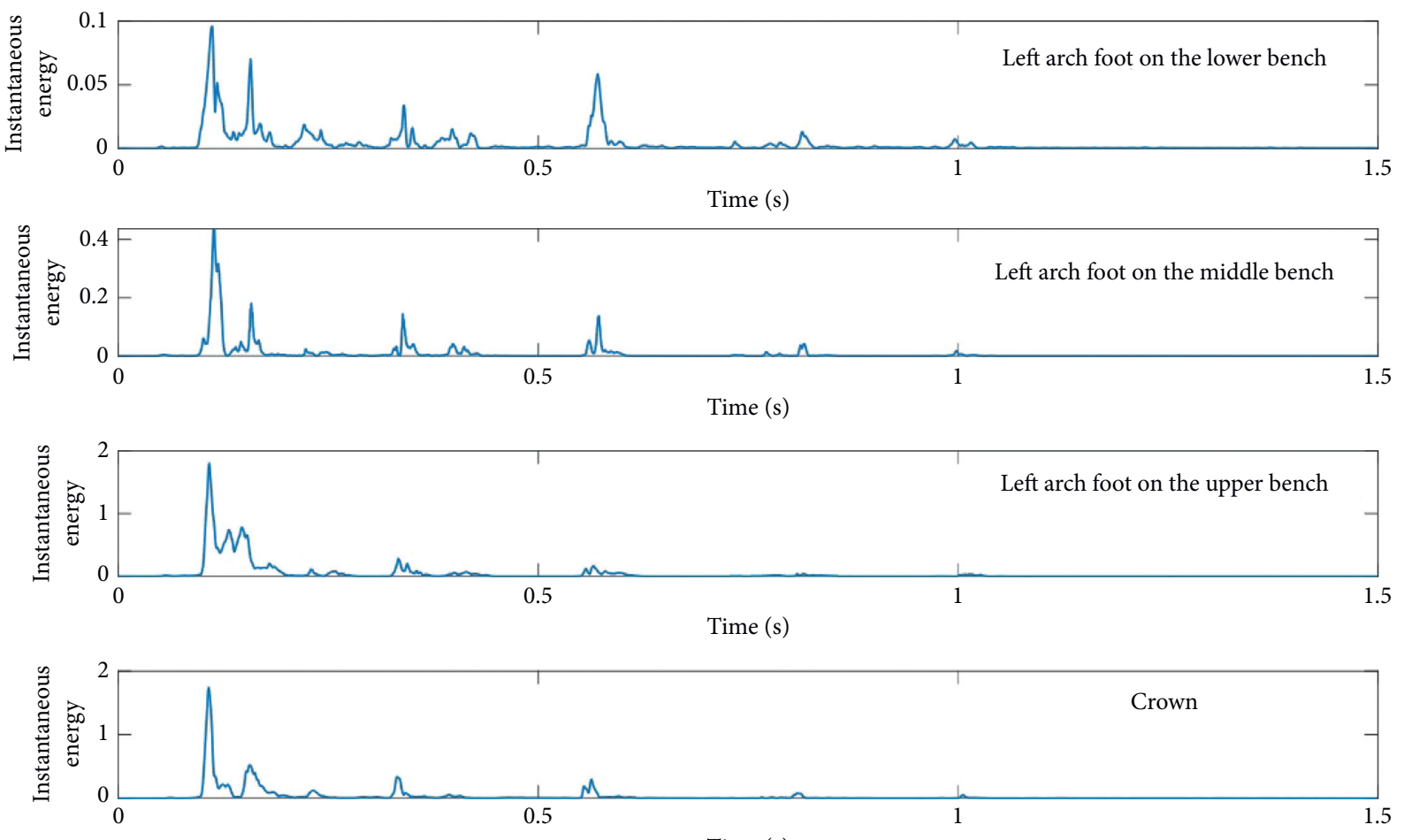

Time (s)
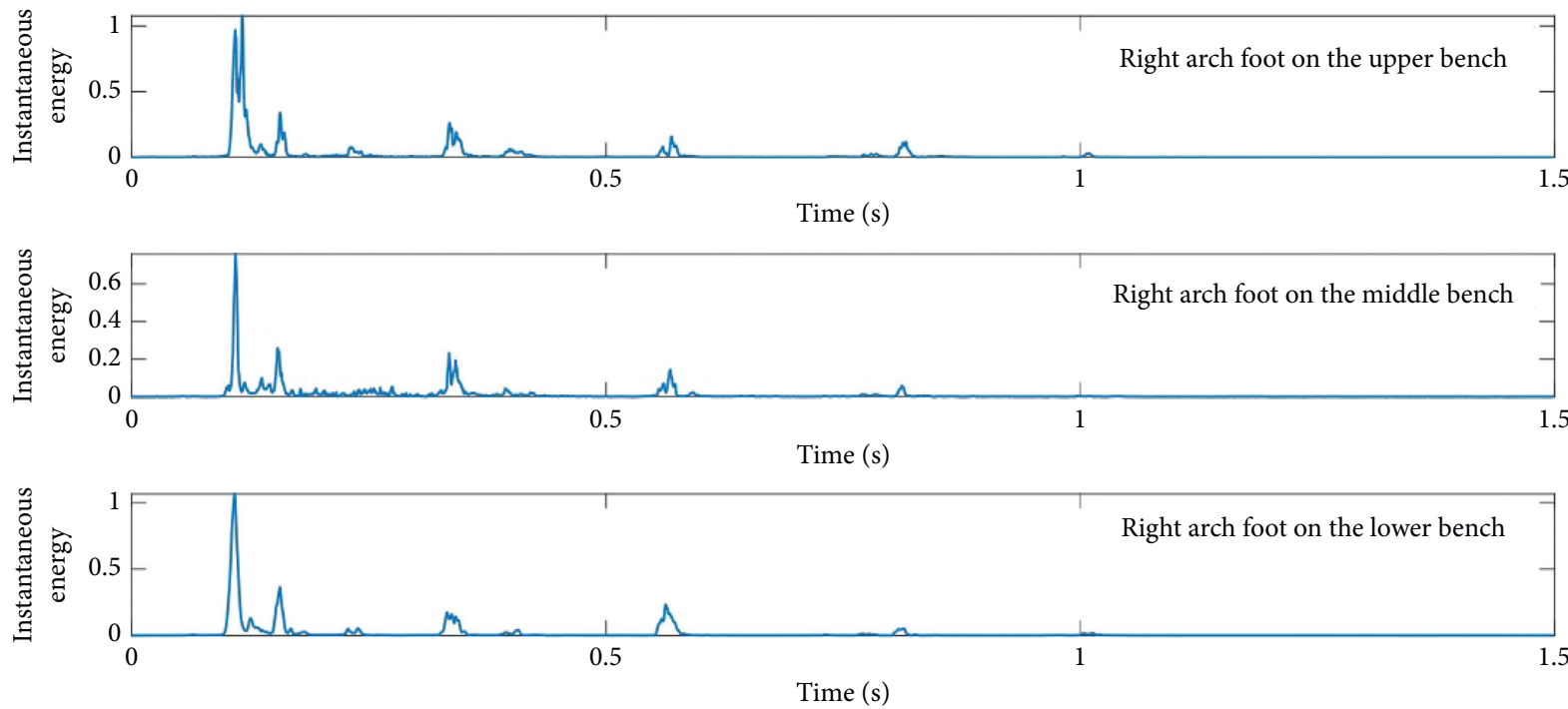

FIgURE 17: Instantaneous energy at different positions of tunnel.

magnitude. This is because the staggered excavation of the left and right arch feet of the lower bench, resulting in a different site condition. The support above the middle step has been completed and the differences of energy dispersion are relatively smaller.

\section{Conclusions}

A detailed field measurement of blasting vibration was carried out in Muzhailing Tunnel with weak rock mass, and the measured data were analyzed using the methods of nonlinear regression analysis, Fourier transform analysis, and HHT analysis. The main conclusions are as follows:
(1) In the longitudinal measurement of the tunnel, in the case of a certain amount of charge, as the blasting distance increases, the spectral width of the blasting vibration frequency becomes narrower, the overall energy is more concentrated, and the frequency tends to move closer to the low frequency. Therefore, it is not true that the greater the distance from the source of the explosion is, the safer the structure will be. If the remaining low frequency is close to the natural vibration frequency of the structure, even if the amplitude is not large, it has a strong destructive effect. In the case of a certain blasting distance, as the amount of charge increases, the frequency of blasting 
vibration will gradually decrease, and the amplitude of the low-frequency region will increase, which will also adversely affect the structure.

(2) In the circumferential measurement of tunnel, the peak vibration velocities at different locations of the tunnel are regressed. From the vault to the arch foot of lower bench, the $K$ values of the regression equation of the radial, tangential, and vertical vibration velocities are continuously decreasing. In particular, in the radial direction, the $K$ value decreases significantly. The $\alpha$ values of the vault and the arch foot of lower bench are generally large, the vibration velocity is attenuated quickly, the arching feet of the upper bench and the middle bench are relatively small, and the vibration velocity attenuation is relatively slow. From the overall trend, as the proportionate charge increases, the tangential frequency decreases more rapidly. The radial main frequency attenuation is relatively slow.

(3) During tunnel blasting excavation, the radial, tangential, and vertical vibration velocities of the supporting structure on the left side of the tunnel are greater than those of the right side of the tunnel. On the one hand, this asymmetry situation is caused by the fact that in order to avoid the feet of steel frames suspending in midair at the same time, the middle bench is excavated with left and right dislocation, resulting in site differences. On the other hand, the stratum inclination affects the propagation of the stress wave, which has a great influence on the vibration velocity.

(4) The frequency distributions of blasting vibration at different positions of the tunnel are different. The left arch foot of the middle bench and the right arch foot of the upper bench have higher vibration frequencies, mainly distributed at $50 \mathrm{~Hz}-200 \mathrm{~Hz}$. The frequencies of the right arch foot of the middle bench and the arch foot of the lower bench are mainly distributed between $60 \mathrm{~Hz}$ and $150 \mathrm{~Hz}$. The frequencies of the vault are relatively low, mainly distributed at $20 \mathrm{~Hz}-150 \mathrm{~Hz}$, while the frequencies of the left arch foot of the upper bench are the lowest, mainly concentrated at $30 \mathrm{~Hz}-70 \mathrm{~Hz}$. It is easy to generate resonance and have an adverse effect on surrounding rock and supporting structures. Hence, it is important to pay attention to the safety of the supporting structure at the left arch foot of the upper bench.

(5) During tunnel blasting, the energy input to the strata media is mainly concentrated in the stage of the blasting of the cut hole, and the input energy of other blastholes is relatively less. The blasting has more energy input to the left arch foot of the upper bench and the tunnel vault, which is consistent with the conclusion of frequency analysis.

\section{Data Availability}

Our data were measured and collected in the construction site, and all the collective data are presented in the figures.

\section{Disclosure}

The author order of this paper has been unanimously agreed on by all authors.

\section{Conflicts of Interest}

The authors declare that they have no conflicts of interest.

\section{Acknowledgments}

This work was funded by the National Natural Science Foundation of China (Grant nos. 41831286 and 51808049). This support is gratefully acknowledged.

\section{References}

[1] T. Lv, Y. Shi, C. Huang et al., "Study on attenuation parameters of blasting vibration by nonlinear regression analysis," Rock and Soil Mechanics, vol. 19, no. 9, pp. 1871-1878, 2007.

[2] C. Xia, Z. Liu, G. Shang, and S. Shen, "Explosive dosage calculation based on blasting vibration velocity and Control value," Modern Tunnelling Technology, vol. 55, no. 4, pp. 163-170, 2018.

[3] C. H. Dowding, Blast Vibration Monitoring and Control, Prentice-Hall, Upper Saddle River, NJ, USA, 1985.

[4] S. Song, S. Li, L. Li et al., "Model test study on vibration blasting of large cross-section tunnel with small clearance in horizontal stratified surrounding rock," Tunnelling and Underground Space Technology, vol. 92, 2019.

[5] Q. Zhang, G. Cheng, and Z. Xu, "Study on propagation law of blasting vibration in open-pit mine based on regression analysis," Mining Research and Development, vol. 38, no. 5, pp. 37-40, 2018.

[6] J. Zhao, Y. X. Zhou, A. M. Hefny et al., "Rock dynamics research related to cavern development for Ammunition storage," Tunnelling and Underground Space Technology, vol. 14, no. 4, pp. 513-526, 1999.

[7] G. Morris, "Vibrations due to blasting and their effects on building structure," The Engineer, vol. 190, pp. 394-395, 1950.

[8] A. Hendron and L. Oriard, "Specifications for controlled blasting in civil engineering projects," International Journal of Rock Mechanics and Mining Sciences \& Geomechanics Abstracts, vol. 34, 1972.

[9] R. Holmberg and P. Perrson, Design of Tunnel Perimeter Blasthole Patterns to Prevent Rock Damage, Nonferrous Metals, New York, NY, USA, 1982.

[10] C. H. Dowding, "Blast and construction vibration monitoring and Control: thirty-five-year perspective," Practice Periodical on Structural Design and Construction, vol. 11, no. 1, pp. 8-12, 2006.

[11] V. V. Krylov, "Ground vibration boom from high-speed trains," Journal of Low Frequency Noise, Vibration and Active Control, vol. 18, no. 4, pp. 207-218, 1999.

[12] X. Sheng, C. J. C. Jones, and M. Petyt, "Ground vibration generated by A load moving along A railway track," Journal of Sound and Vibration, vol. 228, no. 1, 1999.

[13] J. R. Zhou, W. B. Lu, D. W. Zhong, Z. D. Leng, L. Wu, and P. Yan, "Prediction of frequency-dependent attenuation of blast-induced vibration in underground excavation," European Journal of Environmental and Civil Engineering, vol. 2019, pp. 1-18, 2019. 
[14] S. Yang, J. Zhou, and Z. Lv, "Blasting seismic safety monitoring and dynamic analysis of chamber of underground pit and its surrounding rock," China Safety Science Journal, vol. 141, no. 6, p. 148, 2006.

[15] D. Jiang, Y. Hou, S. Ren, F. Li, and Y. Cheng, "Study on the influence of urban large-span tunnel blasting on ground buildings," China Safety Science Journal, vol. 32, no. 7, pp. 99-104, 2008.

[16] Y. Jiang, D. Liu, Y. Wu, F. Xie, D. Yuan, and H. Zhang, "Experimental analysis of blasting vibration of jiaohuayu tunnel on xingyan Expressway in beijing," Tunnel Construction, vol. 38, no. 2, pp. 224-231, 2018.

[17] Z. Rao, The Study of Impacts and Control Standard of Drilling and Blasting Method on Primary Support, Beijing Jiaotong University, Beijing, China, 2010.

[18] H. Meng, "Experimental study on propagation law of tunnel blasting vibration," Railway Engineering, vol. 44, no. 4, pp. 50-54, 2015.

[19] U. Ozer, "Environmental impacts of ground vibration induced by blasting at different rock units on the Kadikoy-Kartal metro tunnel," Engineering Geology, vol. 100, no. $1,2008$.

[20] R. Nateghi, "Prediction of ground vibration level induced by blasting at different rock units," International Journal of Rock Mechanics and Mining Sciences, vol. 48, no. 6, pp. 899-908, 2011.

[21] Y. Zhou and A. Jenssen, "Internal separation distances for underground explosives storage in hard rock," Tunnelling and Underground Space Technology, vol. 24, no. 2, pp. 119-125, 2009.

[22] H. Hao and C. Wu, "Numerical study of characteristics of underground blast induced surface ground motion and their effect on above-ground structures. Part II. Effects on structural responses," Soil Dynamics and Earthquake Engineering, vol. 25, no. 1, pp. 39-53, 2005.

[23] C. Wu and H. Hao, "Numerical study of characteristics of underground blast induced surface ground motion and their effect on above-ground structures. Part I. Ground motion characteristics," Soil Dynamics and Earthquake Engineering, vol. 25 , no. 1, pp. 27-38, 2005.

[24] C. Wu, Y. Lu, and H. Hao, "Numerical prediction of blastinduced stress wave from large-scale underground explosion," International Journal for Numerical and Analytical Methods in Geomechanics, vol. 28, no. 1, pp. 93-109, 2004.

[25] H. Fei, Z. Wang, A. Jiang, M. Liu, X. Li, and H. Yan, "Study on influence of blasting vibration on ground of metro tunnel," Blasting, vol. 35, no. 3, pp. 68-73, 2018.

[26] J. Zhou, W. Lu, L. Zhang, M. Cheng, and P. Yan, “Attenuation of vibration frequency during propagation of blasting seismic wave," Chinese Journal of Rock Mechanics and Engineering, vol. 33, no. 11, pp. 2171-2178, 2014.

[27] W. Yang and B. Yang, "Numerical analysis of explosion seismic effect," Earthquake Engineering and Engineering Dynamics, vol. 45, no. 1, pp. 8-13, 2005.

[28] G. Peng, A Study of the Influence upon the Stability of Tunnel Surrounding Rocks and Primary Support Structure Played by Explosion, Guangxi University, Guangxi, China, 2012.

[29] X. F. Deng, S. G. Chen, J. B. Zhu, Y. X. Zhou, Z. Y. Zhao, and J. Zhao, "UDEC-AUTODYN hybrid modeling of a large-scale underground explosion test," Rock Mechanics and Rock Engineering, vol. 48, no. 2, pp. 737-747, 2015.

[30] X. F. Deng, J. B. Zhu, S. G. Chen, Z. Y. Zhao, Y. X. Zhou, and J. Zhao, "Numerical study on tunnel damage subject to blastinduced shock wave in jointed rock masses," Tunnelling and Underground Space Technology, vol. 43, pp. 88-100, 2014.
[31] J. Xu, C. Yan, H. Bao, J. Chang, P. Sha, and F. Wu, "Research on blasting vibration of soft rock tunnel," Highway, vol. 61, no. 8, pp. 222-228, 2016.

[32] C. Zhang, Numerical Simulation and Application of of Soft Rock Tunnel Blasting Design, Sichuan University, Sichuan, China, 2005.

[33] J.-H. Shin, H.-G. Moon, and S.-E. Chae, "Effect of blast-induced vibration on existing tunnels in soft rocks," Tunnelling and Underground Space Technology, vol. 26, no. 1, pp. 51-61, 2011.

[34] J. X. Chen, W. W. Liu, L. J. Chen et al., "Failure mechanisms and modes of tunnels in monoclinic and soft-hard interbedded rocks: a case study," KSCE Journal of Civil Engineering, vol. 24, no. 4, pp. 1357-1373, 2020.

[35] W. W. Liu, J. X. Chen, L. J. Chen, L. B. Luo, Z. Shi, and Y. F. Wu, "Nonlinear deformation behaviors and a new approach for the classification and prediction of large deformation in tunnel construction stage: a case study," European Journal of Environmental and Civil Engineering, pp. 1-29, 2020.

[36] C. Huang, J. Liu, X. You, B. Wang, and Z. Wang, "Experimental study on propagation law of vibration of blasting,", Science Technology and Engineering, vol. 14, no. 22, pp. 289294, 2014.

[37] Z. Wang, Q. Liu, S. Fu, Z. Liu, and D. Zhu, "Prediction of blasting vibration of boiler tunnel based on segmental fitting of sadovsky formula," Highway, vol. 62, no. 8, pp. 311-315, 2017.

[38] H. Xu, J. Zhang, H. Yang, and X. Zhen, "Investigation on calculating formula of vibration velocity in drilling blasting and its simplification," Journal of Tongji University(Natural Science Edition, vol. 899, no. 7, p. 914, 2007.

[39] J. Henrych and G. R. Abrahamson, "The dynamics of explosion and its use," Journal of Applied Mechanics, vol. 47, no. 1, p. $218,1980$.

[40] W.-b. Lu, Y. Luo, M. Chen, and D.-q. Shu, "An introduction to Chinese safety regulations for blasting vibration," Environmental Earth Sciences, vol. 67, no. 7, pp. 1951-1959, 2012.

[41] F. Gao, A. Hou, X. Yang, and J. Yang, "Analysis of blasting vibration frequency based on dimensional method," Blasting, vol. 27 , no. 3, pp. 1-3, 2010.

[42] Y. Jiao, "Preliminary study on safety assessment criteria for blasting earthquake," Blasting, vol. 5, no. 3, pp. 45-47, 1995.

[43] W. Lv, J. Zhou, M. Cheng, P. Yan, and G. Wang, "Study on attenuation formula of dominant frequency of blasting vibration," Engineering Blasting, vol. 21, no. 6, pp. 1-6, 2015.

[44] H. Ye, X. Yang, and Y. Zhuo, "Experimental study on the attenuation law of main frequency in blasting vibration based on damage accumulation," Mining Research and Development, vol. 39, no. 4, pp. 92-96, 2019.

[45] L. Zhang, M. Gong, and Y. Yu, "Prediction and regression analysis of blasting vibration frequency," Journal of Liaoning Technical University (Natural Science), vol. 4, no. 2, pp. 187-189, 2005. 